\title{
Educação Permanente Saúde: espaços de trocas de saberes experiências entre Agentes Comunitários de Saúde
}

\author{
Permanent health education: spaces are being built in Community Health Agent
}

Permanent health education: los espacios de intercambio de conocimientos y experiencias entre Agente Comunitario de Salud

Alessandra Branco Vallegas ${ }^{1}$, Ândrea Cardoso de Souza $^{2}$, Lívia dos Santos Sanches Carriello ${ }^{3}$

Como citar esse artigo. Vallegas, $\mathrm{AB}$; de Souza, AC; Carriello, LSS. Educação Permanente Saúde: espaços de trocas de saberes e experiências entre Agentes Comunitários de Saúde. Revista PróUniverSUS. 2019 Jul./Dez.; 10 (2): 116-119

\section{Resumo}

Introdução: A educação permanente em saúde favorece os processos de trabalho na medida que possibilita trocas de saberes e experiências entre os integrantes da equipe. No entanto, sua adoção não acontece sem tensionamentos nos serviços. Objetivos: Analisar como os espaços de Educação Permanente Saúde estão sendo construídos nas unidades de saúde da família; conhecer os espaços de trocas de saberes e experiências entre Agentes Comunitários de Saúde e demais integrantes das equipes. Metodologia: trata-se de uma pesquisa descritiva de abordagem qualitativa. O cenário será composto por duas unidades de saúde da família da Área Programática 3.1 do município do Rio de Janeiro e contará com a participação da totalidade dos agentes comunitários de saúde das respectivas unidades. Os dados serão coletados através de entrevista semiestruturada e grupo focal. O projeto foi encaminhado ao Comitê de Ética em Pesquisa do Hospital Universitário Antônio Pedro, da Universidade Federal Fluminense, tendo sido aprovado, $\mathrm{n}^{\circ}$ 10003619.2.0000.5243. A análise dos dados será apoiada nos princípios da Política Nacional de Educação Permanente. Resultados Esperados: como perspectiva, este estudo pretende potencializar e qualificar o processo de trabalho dos Agentes Comunitários de Saúde.

Palavras-chave: Agente Comunitário de Saúde, Atenção Primária à Saúde, Educação Continuada.

\begin{abstract}
Introduction: Permanent health education favors work processes as it enables the exchange of knowledge and experiences among team members. However, their adoption does not happen without tensions in services. Objectives: To analyze how Permanent Health Education spaces are being built in family health units; know the spaces of knowledge and experience exchange between community health agent and other team members. Methodology: This is a descriptive research with a qualitative approach. The scenario will be composed of two family health units from Program Area 3.1 of the city of Rio de Janeiro and will be attended by all the community health agents of the respective units. Data will be collected through semi-structured interviews and focus groups. The project was submitted to the Research Ethics Committee of the Antonio Pedro University Hospital, Fluminense Federal University, and was approved, $\mathrm{n}^{\circ}$ 10003619.2.0000.5243. Data analysis is based on the principles of the National Policy of Permanent Education. Expected Outcomes: As a perspective, this study aims to enhance and qualify his work process of the community health agent. .
\end{abstract}

Keywords: Community Health Agent, Primary Health Care, Continuing Education.

2. Enfermeira. Professora do Programa de Mestrado Profissional em Ensino na Saúde/MPES, UFF, RJ, Brasil. Email: andriacsouza@gmail.com ORCID: https://orcid.org/0000-0002 $-6549-8634$

3. Enfermeira. Mestranda do programa de Mestrado Profissional em Ensino na Saúde/MPES, UFF, RJ, Brasil. Email: liviacarriello@gmail.comm ORCID: https://orcid.org/00000001-6416-1995 


\section{Resumen}

Introducción: la educación sanitaria permanente favorece los procesos de trabajo, ya que permite el intercambio de conocimientos y experiencias entre los miembros del equipo. Sin embargo, su adopción no ocurre sin tensiones en los servicios. Objetivos: analizar cómo se están construyendo espacios de educación permanente en salud en las unidades de salud familiar; Conocer los espacios de intercambio de conocimientos y experiencias entre Agente Comunitario de Salud y otros miembros del equipo. Metodología: Esta es una investigación descriptiva con un enfoque cualitativo. El escenario consistirá en dos unidades de salud familiar del Área de Programa 3.1 del municipio de Río de Janeiro y contará con la asistencia de todos los agentes de salud comunitarios de las respectivas unidades. Los datos se recopilarán a través de entrevistas semiestructuradas y grupos focales. El proyecto fue presentado al Comité de Ética en Investigación del Hospital Universitario Antonio Pedro, Universidad Federal Fluminense, y fue aprobado, $\mathrm{n}^{\circ}$ 10003619.2.0000.5243. El análisis de datos se basa en los principios de la Política Nacional de Educación Permanente. Resultados esperados: Como perspectiva, este estudio tiene como objetivo mejorar el trabajo del agente comunitario y calificar su proceso de trabajo en el equipo de salud familiar.

Palabras clave: Agente de salud comunitaria, Atención primaria de salud, Educación contínua.

\section{Introdução}

A Estratégia de Saúde da Família (ESF) é um dos espaços de atuação do agente comunitário de saúde (ACS) e é considerada pelo Ministério da Saúde o principal dispositivo para reorganização dos serviços de atenção básica à saúde no Brasil. É constituída por uma equipe interprofissional, que é responsável pela população residente em território adstrito e que tem as famílias como foco do cuidado, sendo considerada uma proposta inovadora na atenção à saúde ${ }^{1}$.

A equipe de saúde da família deve ser composta no mínimo por médico, enfermeiro, auxiliar e/ou técnico de enfermagem e agente comunitário de saúde, podendo ser acrescentado a esses profissionais o agente de combate às endemias (ACE) e os profissionais de saúde bucal: cirurgião-dentista, e auxiliar ou técnico em saúde bucal ${ }^{2}$.

Os ACS realizam um papel fundamental junto à equipe de saúde da família, por ser a conexão inicial do trabalho da equipe e com usuário, aquele que recebe e encaminha as demandas individuais e coletivas da comunidade ${ }^{3}$. Dentre suas atribuições, cabe-lhe desempenhar atividades de promoção da saúde, prevenção de doenças e vigilância à saúde, por meio de visitas domiciliares e de ações educativas a serem implementadas junto às famílias da sua área de abrangência, por eles acompanhadas.

A Estratégia Saúde da Família, assim como os demais dispositivos que compõem a Atenção Básica, é normatizada pela Política Nacional de Atenção Básica - PNAB ${ }^{4}$ A última atualização desta política se deu em 2017 trazendo novas atribuições para os ACS.

Para que os ACS desempenhem as atribuições designadas pela nova PNAB, estes precisam de capacitações técnicas para o cumprimento das novas funções. Estes constituem uma nova categoria de trabalhadores, cujo trabalho não demandava uma formação específica. As únicas exigências para o desempenho das atribuições se constituíam em residir próximo às unidades de saúde e integrar a comunidade adstrita local.

Esta nova exigência gera controvérsias. Existem posicionamentos contrários sobre a questão da formação técnica dos ACS. Alguns autores, apontam para perda da potência do trabalho dos ACS descaracterizando seu papel de articulador no território. No entanto, pode se investir em projetos pedagógicos que fortaleçam os saberes desses sujeitos e os mesmos se sintam valorizados ${ }^{5}$.

Está em destaque também na Política Nacional de Atenção Básica a importância da formação e da Educação Permanente em Saúde (EPS) para a adoção de práticas mais condizentes com os princípios e diretrizes do SUS. Em conformidade com a última edição da $\mathrm{PNAB}^{4}$ a EPS pode contribuir para que os profissionais possam problematizar o processo de trabalho, propor ferramentas de melhoria diante das situações vivenciadas e com desejo de ampliar o compromisso e a capacidade crítica e reflexiva dos trabalhadores e gestores.

A EPS é um dispositivo muito importante na qualificação das ações dos ACS. Além de propiciar condições objetivas de aprendizado significativo, baseadas em discussões coletivas e processos reflexivos de situações concretas provenientes do cotidiano de trabalho ${ }^{5}$.

Defendo a educação permanente em saúde para os Agentes Comunitários como ferramenta potencializadora para o cotidiano do seu trabalho.

Nesse contexto os objetivos deste estudo constituem-se em analisar como os espaços de Educação Permanente Saúde estão sendo construídos nas unidades de saúde da família; conhecer os espaços de trocas de saberes e experiências entre Agentes Comunitários de Saúde e demais integrantes das equipes.

\section{Materiais e métodos}

Trata-se de uma pesquisa descritiva de abordagem qualitativa. O método qualitativo de pesquisa é entendido como aquele que se apropria do nível subjetivo e 
relacional da realidade social e é mantido por meio da história, do universo, dos significados, dos motivos, das crenças, dos valores e das atitudes dos atores sociais, se preocupa nas ciências sociais, com um nível de realidade que não pode ser quantificado ${ }^{6}$.

Esta pesquisa terá como cenário duas unidades de atenção primária a saúde localizada na Coordenação de Área Programática (CAP) 3.1 do município do Rio de
Janeiro. Esta área programática compreende os bairros Complexo do Alemão, Complexo da Maré, Penha, Ramos, Vigário Geral e Ilha do Governador e possui aproximadamente 886.551 habitantes 7 .

Para fins de vigilância epidemiológica, este território é dividido em seis regiões administrativas conforme o quadro abaixo:

Quadro I. Distribuição das regiões administrativas da CAP 3.1, Rio de Janeiro

\begin{tabular}{|c|c|c|}
\hline $\begin{array}{l}\text { Regiões } \\
\text { Administrativas }\end{array}$ & Bairros & Subprefeitura Responsável \\
\hline \multirow{4}{*}{$\mathrm{X}$ - Ramos } & Bonsucesso & Zona Norte 3 (Ilha) \\
\hline & Manguinhos & Zona Norte 2 \\
\hline & Olaria & Zona Norte 3 (Ilha) \\
\hline & Ramos & Zona Norte 3 (Ilha) \\
\hline \multirow{3}{*}{ XI - Penha } & Brás de Pina & Zona Norte 1 \\
\hline & Penha & $\begin{array}{c}\text { Zona Norte 1/ ZN } 2 \\
\text { (Complexo) }\end{array}$ \\
\hline & Penha Circular & Zona Norte 1 \\
\hline \multirow{12}{*}{$\begin{array}{l}\mathrm{XX} \text { - Ilha do } \\
\text { Governador }\end{array}$} & Bancários & \multirow{12}{*}{ Zona Norte 3 (Ilha) } \\
\hline & Cacuia & \\
\hline & Cidade Universitária & \\
\hline & Cocotá & \\
\hline & Freguesia & \\
\hline & Galeão & \\
\hline & Jardim Carioca & \\
\hline & Jardim Guanabara & \\
\hline & Moneró & \\
\hline & Pitangueiras & \\
\hline & Portuguesa & \\
\hline & Zumbi & \\
\hline $\begin{array}{c}\text { XXIX - Complexo do } \\
\text { Alemão }\end{array}$ & $\begin{array}{l}\text { Complexo do } \\
\text { Alemão }\end{array}$ & Zona Norte 2 \\
\hline XXX - Maré & Maré & Zona Norte 3 (Ilha) \\
\hline \multirow{4}{*}{ XXXI - Vigário Geral } & Cordovil & \multirow{4}{*}{ Zona Norte 1} \\
\hline & Jardim América & \\
\hline & Parada de Lucas & \\
\hline & Vigário Geral & \\
\hline
\end{tabular}

Fonte: Censo IBGE 2010, Portal Georio (www.portalgeo.rio.rj.gov.br), Armazém de Dados - IPP.

Os participantes deste estudo serão todos os 40 agentes comunitários de saúde que integram 08 equipes de saúde da família de uma Clínica da Família e de um Centro Municipal de Saúde localizados no bairro de Vigário Geral. Essas unidades foram selecionadas pelo fato de atuar e já ter atuado durante cinco anos e possuir vínculo com os futuros participantes da pesquisa e conhecer o processo de trabalho desempenhado por eles e suas equipes. Os mesmos serão convidados para participar do estudo e receberão o termo de consentimento livre e esclarecido.

Será adotado como critério de inclusão: a 
totalidade dos profissionais que trabalham como agentes comunitários de saúde em duas unidades de saúde da família localizadas na CAP 3.1 do município do Rio de Janeiro. Será utilizado como critérios de exclusão os profissionais que estiverem de férias.

A técnica de coleta de dados para o estudo proposto será a entrevista com roteiro semiestruturado e grupo focal a fim de viabilizar maior participação dos profissionais.

As entrevistas semiestruturadas baseiam-se em um roteiro constituído de perguntas abertas, feitas por uma ordem prevista, podem ser definidas como uma lista de informações que se deseja de cada entrevistado, mas que podem variar de acordo com as características de cada um ${ }^{8}$.

Com intuito de maior aproximação com os participantes da pesquisa e viabilizar maior apreensão dos dados além da entrevista, prevê-se a realização de grupos focais que trata-se de uma técnica que pode ser usada quando o foco de trabalho do pesquisador é o grupo, os pesquisadores encontram nos grupos focais uma técnica que os ajuda na investigação de crenças, valores, atitudes, opiniões e processos de influência grupal, bem como dá suporte para a geração de hipóteses, construção teórica e a elaboração de instrumentos?.

As entrevistas e os grupos serão gravados por aparelhos de áudio e serão agendadas no próprio local de trabalho dos participantes em horários pertinentes a eles visando um menor desgaste dos entrevistados.

Ainterpretaçãodos dados preconizaum tratamento diferenciado para a organização e sistematização dos dados, a partir deste momento iremos estabelecer articulações entre os dados e os referenciais teóricos da pesquisa, respondendo às questões da pesquisa com base em seus objetivos. Promoveremos deste modo, relações entre o concreto e o abstrato, o geral e o particular, a teoria e a prática. Sendo assim os dados serão agrupados em conformidade com as temáticas permitindo uma análise mais aprofundada ${ }^{6}$.

A análise dos dados será apoiada nos princípios da Política Nacional de Educação Permanente e se constituirá numa análise temática. Após a transcrição da íntegra das entrevistas e do grupo focal será procedido o agrupamento das narrativas por temas. Neste momento, serão definidas categorias temáticas que propiciarão a análise dos resultados.

A pesquisa, no que tange aos preceitos éticos seguirá os princípios da Resolução 466/12. O projeto foi submetido à aprovação no Comitê de Ética em Pesquisa do Hospital Universitário Antônio Pedro/Niterói/RJ, parecer 10003619200005243.

\section{Resultados esperados}

Este estudo pretende potencializar o trabalho do ACS e qualificar seu processo de trabalho, tornar possível reconstruir conceitos e redirecionar as estratégias educativas das equipes envolvidas dentro de uma lógica semelhante à Política Nacional de Educação Permanente em Saúde.

A Educação Permanente significa aprendizagem no trabalho, onde o aprender e o ensinar se incorporam ao quotidiano das organizações e ao trabalho. Propõese algumas referências nos processos de capacitação dos trabalhadores, considerando as necessidades de saúde das pessoas e das populações, da gestão setorial e do controle social em saúde, tendo como objetivos a transformação das práticas profissionais e da própria organização do trabalho e sejam estruturados a partir da problematização do processo de trabalho ${ }^{10}$.

Ter os agentes comunitários de saúde não só como internúncios e executor de tarefas, mas como articuladores e elaboradores de mecanismos que busquem melhorar o acesso e a qualidade do serviço de saúde. Para isso, é necessário comprometimento da equipe com seu trabalho e implicação com os cidadãos que fazem uso do Sistema Único de Saúde, sentir-se sujeitos deste processo, pois ainda que sob uma das mais difíceis condições de trabalho, tanto do ponto de vista estrutural, quanto de segurança laboral, sempre é possível melhorar e transformar através da educação.

\section{Referências}

1. Silva SS. et al. In: O agente comunitário de saúde: o uso da educação em saúde como facilitadora do cuidado. 2014. Disponível em http://www. seer.ufu.br/index.php/revextensao/article/viewFile/28956/16086. Acesso em 13/09/2018.

2. Brasil, Ministério da Saúde. Departamento de Atenção Básica. http://dab. saude.gov.br/portaldab/ape esf.php?conteudo=agente comunitario_saude. Acesso em 11/09/2018

3. Malfitano APS. Lopes RE et. al. In. Educação Popular, ações em saúde, demandas e intervenções sociais: o papel dos agentes comunitários de saúde. Cad CEDES. 2009; 29(79):361-72.

4. Brasil, Ministério da Saúde. Política Nacional de Atenção Básica, 2017 http://portalarquivos.saude.gov.br/images/pdf/2017/setembro/04/1a-PNAB2017.pdf. Acesso em 11/09/2018.

5. Queiroz MD. et al. In: Educação permanente com os agentes comunitários de saúde: potencialidades de uma formação norteada pelo referencial da Educação Popular em saúde , 2013. Disponível em https://www.scielosp. org/article/ssm/content/raw/?resource ssm path=/media/assets/icse/ v18s2/1807-5762-icse-18-s2-1199.pdf. Acesso em: 30 de maio de 2018.

6. Minayo MCS. et. Al. In. Análise qualitativa: teoria, passos e fidedignidade. Ciência Saúde Coletiva vol. 17, no 03 Rio de janeiro, março 2012.

7. Censo IBGE 2010, Portal GeoRio. Disponível em: www.portalgeo.rio. rj.gov.br. Armazém de Dados - IPP. Acesso em 30/05/2018.

8. Laville C, Dionne J. A construção do saber: manual de metodologia da pesquisa em ciências humanas. Belo Horizonte: UFMG, 1999.

9. Gondim SMG et. al. In. Grupos Focais como Técnica de Investigação Qualitativa: desafios metodológicos. Paidéia, 2003, 2, 149-161.

10. Brasil, Ministério da Saúde. Portaria nº 198/GM/MS. Brasília, 2004. 